\title{
HEXAMUF INTERIOR DESIGN SEBAGAI SOLUSI KETERBATASAN RUANG PADA KAPAL WISATA
}

\author{
*Agung Prasetyo Utomo, Septaviola Dini Utami, Rizki Aris Setyawan dan Ahmad Andrei Setiawan \\ Prodi Teknik Perancangan dan Konstruksi Kapal Politeknik Perkapalan Negeri Surabaya \\ *agung_pu@ppns.ac.id
}

\begin{abstract}
Abstrak
Desain Interior adalah proses merancang dan merencanakan suatu ruangan dengan mengedepankan aspek keindahan, kenyamanan, dan fungsi dari ruangan tersebut. Dengan seiring berkembangnya waktu sebuah ruangan dituntut dapat memberikan fungsi lebih dengan didukung furniture yang memadai walaupun dengan kapasitas ruangan yang terbatas layaknya ruangan pada sebuah kapal. Pada penelitian ini akan merancang sebuah furniture dengan fungsi primer dan beberapa fungsi sekunder sehingga dapat mengurangi penggunaan furniture yang lebih banyak pada ruang. Penelitian ini menerapkan perhitungan antropometri sehingga menghasilkan dimensi furniture yang ergonomis dan ramah terhadap bentuk tubuh manusia. Selain itu rancangan yang dibuat tidak meninggalkan segi keindahan dengan mengambil konsep minimalis modern. Rancangan ini mengambil sebuah bentuk alam dari sarang lebah yang dianggap memilki keunggulan dalam segi strukutur dan mudah dipadupadankan satu sama lain. Penelitian ini menghasilkan sebuah desain sofa sebagai fungsi primer sebagai tempat duduk dan tempat tidur, serta fungsi sekunder sebagai meja dan kursi. Sofa ini dapat dibongkar pasang sesuai kebutuhan sehingga didapatkan fungsi sekundernya yang sangat cocok digunakan pada ruang yang tidak terlalu luas layaknya ruangan pada kapal wisata.
\end{abstract}

Kata Kunci: Interior, Furniture, Hexamuf, Kapal Wisata.

\begin{abstract}
Abstrct
Interior design is the process of designing and planning a room by prioritizing the aspects of beauty, comfort, and function of the room. With the development of time, a room is required to provide more functions supported by adequate furniture even with a limited space capacity like the room on a ship. This research will design an item of furniture with a primary function and several secondary functions so that it can reduce the use of more furniture in space. This study applies anthropometric calculations to produce ergonomic furniture dimensions and is friendly to the human body shape. Besides, the design made does not leave the beauty aspect by taking a modern minimalist concept. This design takes a natural form from a beehive which is considered to have advantages in terms of structure and is easy to mix and match with one another. This research produces a sofa design as a primary function as a seat and bed, and a secondary function as a table and chairs. This sofa can be assembled as needed so that it gets a secondary function which is very suitable for use in a space that is not too large like the room on a tourist ship.
\end{abstract}

Keyword: Interior, Furniture, Hexamuf, Tourist Ship.

\section{PENDAHULAN}

Transportasi laut memegang peranan yang sangat penting di negara kepulauan, terdapat tiga aspek yang saling terkait satu sama lain, yaitu lalu lintas dan sarana angkutan laut, kepelabuhanan, keselamatan dan keamanan pelayaran. Pada dasarnya kapal merupakan bangunan darat yang diperuntukkan agar bisa mengapung di air dengan ketersediaan ruang yang cukup untuk berlayar lama dan umumnya tidak seluas bangunan yang ada di daratan. Terlebih lagi jika kapal tersebut bukan kapal penumpang, sehingga ruangan yang tersedia sangat terbatas untuk aktivitas penumpang. Namun ruangan tersebut dituntut memberikan fungsi yang optimal untuk menunjang kinerja awak kapal beserta muatannya. Lain halnya dengan kapal wisata, disediakan sebagai transportasi wisata asing maupun lokal untuk berbagai aktivitas di wilayah pariwisata. Beberapa penelitian 
sebelumnya tentang yang membahas tentang aspek ergonomi telah banyak dilakukan, diantaranya [1] dengan melakukan penelitian terhadap 4 jenis kursi kuliah yang diteliti menunjukkan $77 \%$ kursi dari jenis Siwangi dapat digunakan dengan nyaman dan sesuai dengan anthropometri pengguna. Kursi jenis lain khususnya kursi kayu besi dan kursi Chettos hanya dapat digunakan kurang dari $30 \%$ populasi pengguna karena dimensi yang tidak sesuai dengan anthropometri rerata pengguna. Desain Prototipe Meja dan Kursi Pantai Portabel dengan Integrasi Pendekatan Ergonomi [2], Value Engineering dan Kansei Engineering diperoleh hasil Desain meja dan kursi makan portabel yang dibutuhkan pengunjung dan pemilik rumah makan merupakan desain yang menggunakan konsep folding dan combination Konsep bentuk combina-tion/modular dapat memudahkan penataan dan menyesuaikan kebutuhan. Desain Furnituree Meja dan Kursi Multifungsi untuk Apartemen Tipe Studio diperoleh hasil berupa berupa meja dan kursi multifungsi [3]yang bisa digunakan sebagai meja makan, meja kerja dan meja tamu, dan kursi multifungsi yang bisa digunakan sebagai kursi makan, kursi kerja, dan kursi tamu [4][5]. Berdasarkan hal tersebut, penulis melakukan penilitian dengan pemanfataan furniture berupa sofa multifungsi berbentuk Hexagonal (Hexamuf) dengan dengan konsep minimalis modern dengan sebagai solusi keterbatasan luas ruangan pada kapal wisata.

\section{METODE}

\subsection{Metodologi Penelitian}

Metode penelitian yang digunakan dalam penelitian ini dijelaskan dalam diagram berikut:

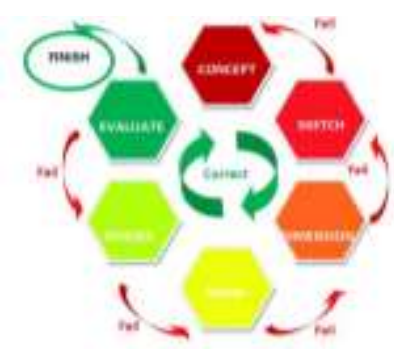

Gambar 1. Metodologi Perancangan

Pertama, hal yang dilakukan adalah pemilihan konsep dalam mendesain dengan memperhatikan code dan standar yang telah ada. Kedua, membuat sketsa yang berupa gambar abstrak. Ketiga, sketsa yang telah dibuat, diproses, direalisasikan dengan memperhatikan studi keilmuan yang digunakan. Keempat, proses menggambar mulai dari tahap konsep hingga menjadi gambar yang dimensi yang sesuai. Kelima, render merupakan proses gambar dengan menggunakan gambar 3D. Gambar 3D biasanya menggunakan aplikasi CADD. Keenam, melakukan evaluasi terhadap produk, kesesuaian produk dengan fungsi yang telah ditentukan.

\subsection{Kapal Wisata}

Kapal wisata di gunakan secara khusus untuk rekreasi dan menikmati wisata laut. Kebanyakan para penumpang yang menyewa kapal tersebut untuk menghabiskan waktunya untuk berjemur, snorkling, diving , dan menikmati pemandang dari atas kapal maupun di air.

\subsection{Furniture Multifungsi}

Pada dasarnya furnituree multifugsi memiliki fungsi yang sama dengan furnituree yang lain, akan tetapi furniture multifungsi memiliki nilai fungsi lebih. Karena dari segi ergonomi dan ekonomi menjadi alasan furniture tersebut banyak diminati. Furnituree jenis ini cocok untuk ruangan yang sempit.

\subsection{Desain sarang lebah madu}

Desain sarang yang berbentuk hexagonal memiliki fungsi tersendiri. Beberapa hasil penelitian menujukkan segienam merupakan bentuk teroptimal jika ditinjau dalam geometri matematika karena dibandingkan bentuk segi-n lainnya segienam memiliki luas kapasitas yang paling besar dengan keliling yang kecil sehingga memerlukan bahan baku pembuatan sarang yang sedikit. 
Antropometri

Antropometri merupakan bidang ilmu yang berhubungan dengan dimensi tubuh manusia. Rancangan yang mempunyai kompatibilitas tinggi dengan manusia yang memakainya sangat penting untuk mengurangi timbulnya bahaya akibat terjadinya kesalahan kerja karena faktor kesalahan dalam merancang (design-induced error). Pemakaian nilai-nilai percentil yang umum diaplikasikan dalam 45 perhitungan data antropometri dapat dijelaskan dalam tabel 1 , sebagai berikut :

Tabel 1. Macam Percentil dan Cara Perhitungan dalam Distribusi Normal

\begin{tabular}{ll}
\hline Percentile & Perhitungan \\
\hline 1-St & $\mathrm{X}-2,325 \sigma \chi$ \\
$2,5-$ th & $\mathrm{X}-1,96 \sigma \chi$ \\
5 - th & $\mathrm{X}-1,645 \sigma \chi$ \\
10 - th & $\mathrm{X}-1,28 \sigma \chi$ \\
$50-$ th & $\mathrm{X}$ \\
90 - th & $\mathrm{X}+1,28 \sigma \chi$ \\
95 - th & $\mathrm{X}+1,645 \sigma \chi$ \\
$97,5-$ th & $\mathrm{X}+1,96 \sigma \chi$ \\
$99-$ th & $\mathrm{X}+2,325 \sigma \chi$ \\
\hline
\end{tabular}

\subsection{Estetika}

Estetika merupakan kondisi yang berkaitan dengan keindahan yang dapat dirasakan, namun keindahan itu baru dapat dirasakan jika terjalin perpaduan harmonis antara elemen-elemen keindahan yang terkandung dalam suatu obyek meliputi simetri/asimetri, pola, warna, kontras, perspektif, gerak, ekspresi, irama, kesatuan (unity), harmoni, keseimbangan (balance), bentuk dan proporsi serta beberapa prinsip estetika lainnya.

\section{HASIL DAN PEMBAHASAN}

\subsection{Konseptualisasi}

Proses pertama dari sebuah desain adalah menentukan konsep yang akan diambil sebelum berjalan ke proses berikutnya. Kali ini desainer akan mengambil konsep furniture yang mengimplementasikan bentuk-bentuk alam yang futuristik dan mudah diterapkan. Sarang Lebah Madu memiliki keistimewaaan jika ditinjau dalam perspektif matematika dimana bentuk segienam beraturan merupakan bentuk geometri memungkinkan dalam pembuatan sarangnya tidak terdapat celah antara satu rongga kamar lainnya.

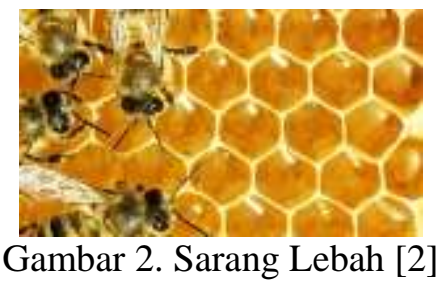

\subsection{Sketsa}

Sketsa adalah proses perencaan desain yang masih terkait dalam konseptualisasi desain. Namun, pada proses ini sudah bisa dihasilkan gambar abstrak dari desain utama yang akan dihasilkan. Pada bentuk utama sketsa dari produk yang akan dibuat yang selajutnya akan diproses dalam penentuan dimensi serta proses desain yang lebih detail. 


\subsection{Perencanaan Dimensi}

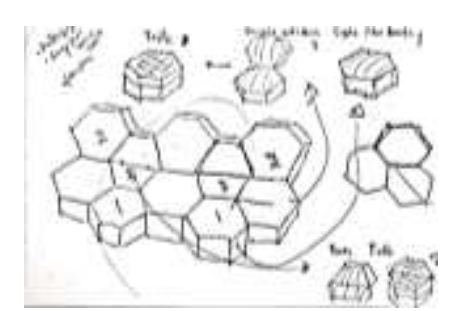

Gambar 3. Sketsa bentuk

Perencanaan Dimensi merupakan tahap dimana desain bisa direalisasikan menjadi produk sesungguhnya . Pada pembuatan dimensi dasar penentuan dengan mengikuti pendekatan Antropometri. Pemakaian nilai-nilai percentil yang umum diaplikasikan dalam 45 perhitungan data antropometri dapat dijelaskan dalam tabel 2 , sebagai berikut :

Tabel 2. Percentile

\begin{tabular}{ll}
\hline Percentile & Perhitungan \\
\hline 1-St & $\mathrm{X}-2,325 \sigma \chi$ \\
2,5 - th & $\mathrm{X}-1,96 \sigma \chi$ \\
$5-$ th & $\mathrm{X}-1,645 \sigma \chi$ \\
$10-$ th & $\mathrm{X}-1,28 \sigma \chi$ \\
50 - th & $\mathrm{X}$ \\
90 - th & $\mathrm{X}+1,28 \sigma \chi$ \\
95 - th & $\mathrm{X}+1,645 \sigma \chi$ \\
$97,5-$ th & $\mathrm{X}+1,96 \sigma \chi$ \\
$99-$ th & $\mathrm{X}+2,325 \sigma \chi$ \\
\hline
\end{tabular}

Tabel tersebut merupakan rumus pendekatan dari perhitungan persentil dalam distribusi normal. perhitungan persentil yang sering digunakan yaitu dengan kombinasi batas sampel 5\% dan 95\%, yang mana diantara rentang tersebut dimensi yang dihasilkan tidak memberikan perbedaan yang signifikan kepada para penggunanya. Penggunaan persentil $5 \%$ atau $95 \%$ tersebut menyesuaikan dari dimensi apa yang ingin ditentukan.

Tabel 3. Data Antroprometri 4 orang responden (mm)

\begin{tabular}{lllllll}
\hline No & Dimensi Tubuh & A & B & C & D & X \\
\hline 1 & Lebar bahu & 440 & 440 & 480 & 430 & 448 \\
2 & Tinggi lipat lutut & 445 & 455 & 450 & 500 & 463 \\
3 & Jarak lipat lutut ke pantat & 460 & 460 & 440 & 580 & 485 \\
4 & Lebar panggul & 320 & 330 & 360 & 360 & 343 \\
5 & Tinggi siku pada posisi duduk & 260 & 160 & 130 & 170 & 180 \\
6 & Jarak siku ke ujung jari & 440 & 460 & 480 & 530 & 477.5 \\
\hline
\end{tabular}

Data tersebut diperoleh dari data sekunder antropometri 4 orang Indonesia. A, B, C, D adalah Data responden (mm) dan X adalah Rata-rata (mm).

Tabel 4. Hasil perhitungan Antropometri 4 orang

\begin{tabular}{llllll}
\hline No & Dimensi Tubuh & $\sigma \chi$ & X & 95-th & 5-th \\
\hline 1 & Lebar bahu & 26 & 448 & 491 & - \\
2 & Tinggi lipat lutut & 26 & 463 & - & 421 \\
3 & Jarak lipat lutut ke pantat & 27 & 485 & - & 441 \\
4 & Lebar panggul & 24 & 343 & 383 & - \\
5 & Tinggi siku pada posisi duduk & 31 & 180 & 130 & - \\
6 & Jarak siku ke ujung jari & 8 & 477.5 & - & 163 \\
\hline
\end{tabular}

Keterangan Tabel 4 yaitu $\sigma \chi$ adalah standart devisiasi, 95-th merupakan persentil ke-95 dan 5-th persentil ke5. Berdasarkan perhitungan data antropometri pada Tabel 4 diatas diperoleh hasil dimensi berupa, panjang (c) (i) copyright is published under Lisensi Creative Commons Atribusi 4.0 Internasional. 
tempat duduk $441 \mathrm{~mm}$, lebar tempat duduk 509,23 mm (menyesuaikan bentuk heksagon beraturan), tinggi tempat duduk $421 \mathrm{~mm}$, lebar back seat sama dngan lebar tempat duduk sebesar 509,23 $\mathrm{mm}$ dan tinggi sandaran (back seat) sama dengan panjang tempat duduk yaitu $441 \mathrm{~mm}$.

\subsection{Proses Pembuatan Gambar dan Rendering}

Setelah dilakukan kriteria diatas, maka tahap selanjutnya dilakukan proses penggambaran yang dimulai dari konsep awal desain, sketsa dan dimensi yang sesuai. Pada proses ini dilakukan menggunakan bantuan CADD 3D dilanjutkan dengan Rendering hingga diperoleh hasil yang menyerupai gambaran nyata dalam bentuk 3D.

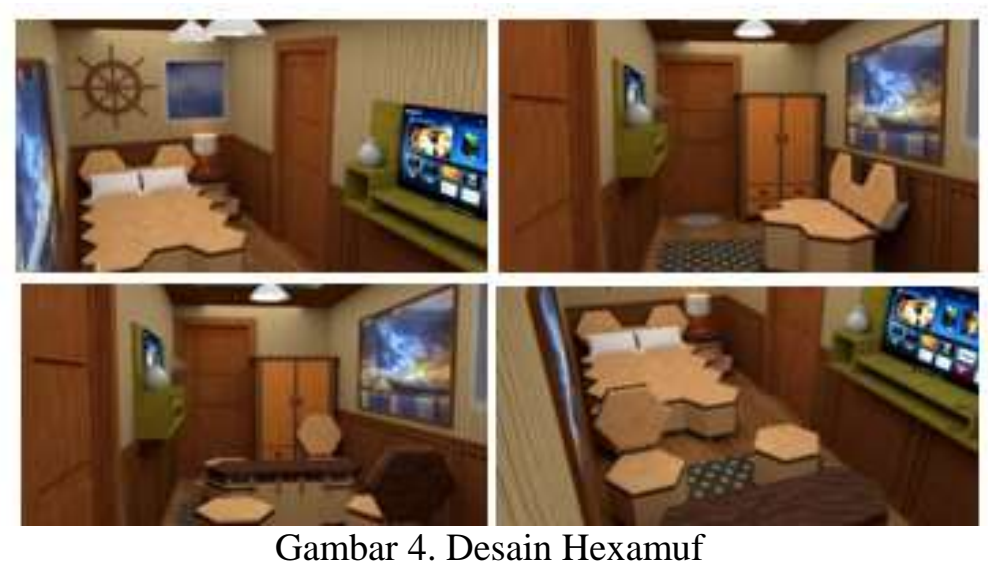

Gambar 4 adalah hasil desain hexamuf dengan keterbatasan ruang yang dibentuk sebagai tempat tidur pada kapal wisata. Desain selanjutnya adalah fungsi lain dari hexamuf sebagi sofa dan kursi yang dapat dibongkar pasang sesuai dengan kebutuhan atau kegiatan yang dilaksanakan dapat dilihat pada gambar 5 dan 6. Dari gambar 7 diatas menggambarkan fungsi primer dan sekunder dari desain Hexamuf sebagai solusi keterbatasan ruang, dengan memperhatikan konsep antropometri penumpang (orang indonesia) namun tetap menonjolkan kesan mewah dan estetika pada kapal wisata.

\section{KESIMPULAN}

Desain furniture sofa multifungsi memanfatkan bentuk Hexagonal (Hexamuf) memberi solusi pada ketebatasan ruang. Bentuk yang unik dan menarik serta tetap berpedoman pada antropometri penumpang kapal wisata. Desain Hexamuf memiliki fungsi primer sebagai tempat duduk dan tempat tidur, serta meja dan kursi sebagai fungsi sekunder yang dapat dibongkar pasang sesuai kebutuhan. Pemilihan dimensi dan material marine use yang digunakan bisa memberi nilai tambah dari segi kenyamanan, fungsi serta aspek keselamatan dalam penggunaannya sehinggga pengguna kapal wisata dapat lebih menikmati. Pengembangan selanjutnya akan dilakukan beberapa tambahan inovasi yang sesuai dengan perkembangan teknologi maupun penggunaan namun tetap berkonsep multifungsi dan efisien pada beberapa ruang kapal yang terbatas ukurannya.

\section{DAFTAR PUSTAKA}

[1] Grace Mulyono, Jurusan Desain Interior, Fakultas Seni dan Desain, Universitas Kristen Petra - Surabaya, Dimensi Interior, Vol. 8, No. 1, JUNI 2010: 44-51 46

[2] Desain Prototipe Meja dan Kursi Pantai Portabel dengan Integrasi Pendekatan Ergonomi, Value Engineering dan Kansei Engineering, Nora Yuanita Restantin1, Mirwan Ushada1*, Makhmudun Ainuri1, Jurnal Teknik Industri, Vol. 14, No. 1, Juni 2012, 53-62 ISSN 1411-2485 print / ISSN 2087-7439 online

[3] Desain Furnitur Meja dan Kursi Multifungsi untuk Apartemen Tipe Studio, Penulis Tagor Sean Reinhard, dan Drs. Taufik Hidayat MT., Jurnal Sains Dan Seni Pomits Vol. 3, No.1, (2014) 2337-3520 (2301-928X Print)

[4] Ahmad Abtokhi, Dkk. 2007). Pertimbangan Antropometri pada Pendesainan. Yogyakarya: Seminar Nasional III SDM Teknologi Nuklir.

[5] Tri Prasetyo Utomo. 2010. Estetika Arsitektur dalam Perspektif Teknologi dan Seni. Surakarta: Fakultas Seni Rupa dan Desain ISI Surakarta.

copyright is published under Lisensi Creative Commons Atribusi 4.0 Internasional. 